\title{
Influence of Anionic and Non-Ionic Surfactants on Nanoparticle Synthesis by Solvent-Free Extrusion Emulsification
}

Tomislav Ivancic ${ }^{1}$, Michael R. Thompson ${ }^{1}$, John L. Pawlak ${ }^{2}$, David J. W. Lawton ${ }^{3}$

\author{
${ }^{1}$ Department of Chemical Engineering, McMaster University, Hamilton, Ontario, Canada \\ ${ }^{2}$ Xerox Corporation, Rochester, NY, USA \\ ${ }^{3}$ Xerox Research Center of Canada, Mississauga, Ontario, Canada
}

* Author to whom correspondence should be addressed.

Tel: (905) 525-9140 x 23213

Email: mthomps@mcmaster.ca 


\begin{abstract}
This study examines the impact of surfactants on the mechanism of a new solvent-free extrusion emulsification (SFEE) technique. Two sets of surfactants were used in this work, three anionic (SDBS, Unicid 350, Calfax DB-45) and three non-ionic (Igepal CO-890, Brij 58, Synperonic F-108). Of the anionic surfactants, only SDBS and Calfax were found to create stable $\mathrm{O} / \mathrm{W}$ emulsions with a polyester in the desired 100-200 $\mathrm{nm}$ size range; the latter requiring a lower molar concentration. Igepal CO-890 and Brij 58 resulted in only partial emulsification despite requiring higher molar loadings than their anionic counterparts to accomplish this outcome, with majority of the polymer leaving the extruder without phase inverting. The study reinforced previous findings that the dispersion stage (zone) controls the SFEE technique, and highlighted the importance of water affinity displayed by a surfactant species to compensate for high retarding viscous force for mixing water into the polymer melt.
\end{abstract}

\title{
Keywords
}

twin screw extruder; surfactants; emulsion; coalescence 


\section{Introduction}

Nanoparticles have been gaining major attention over the past decade, and are being utilized in various applications such as adhesives, printing technologies, construction materials, and pharmaceuticals. There exist numerous methods for preparing nanoparticles, but the preferred top-down approach is production by phase inversion emulsification (PIE). Industrially, particles are formed in a solvent-based PIE process (solvent emulsification, SE) where the polymer, dissolved in an organic solution, is dispersed in an excess of water. Many variables such as temperature, mixing speed, choice of solvent and $\mathrm{pH}$ impact the particle size and size distribution of a resulting emulsion, but overall SE is robust and easily scalable [1-4]. However, use of an organic media in this process has lost popularity due to the high material cost, substantial energy requirements for removal, and restricted handling due to strict environmental regulations. The batch-like nature of SE is another aspect where improvements would be desirable since yields will be lower than continuous processes. Greener alternatives are currently being sought to directly disperse the polymer phase within water, but they bring many challenges. This paper focuses on a new continuous manufacturing process conducted in a twin-screw extruder (TSE) that avoids the need for solvents to create stable emulsions with high viscosity polymers.

Solvent-free extrusion emulsification (SFEE) operates without solvent, solely utilizing water as the liquid medium to create particles as small as $100-200 \mathrm{~nm}$ with high viscosity polymers (up to $600 \mathrm{~Pa}$.s has been tested to date) [5-7]. Variants of this emulsification technique have been proposed by several companies for commercialization, as seen in the patent literature [8-13]. We separate processes in the TSE into three distinct zones or stages, namely melting, dispersion, and dilution. The dispersion stage seems to hold the critical role of gradually incorporating water into the bulk polymer phase with the aid of surface active agents, whereas the dilution stage controls 
the subsequent phase inversion creating the desired oil-in-water $(\mathrm{O} / \mathrm{W})$ emulsion; the rate of lamellae thinning for the melt/water system in the dispersion stage directly impacts final particle size [14], which must be relatively fast to fit within the available length of the extruder (approximately $50 \%$ of the overall machine length). The technique has notable needs for higher concentrations of surfactant compared to solvent-based PIE due to the rate of lamellae thinning required and high viscosity medium, which impacts production costs as well as applications for the final particles. A better understanding of the role of surfactants in SFEE would give processors more control over features of the final particles generated by the technique. This paper analyzes surfactant use based on a comparison of emulsification between SE and SFEE.

Use of a solvent in SE is responsible for lowering the overall system viscosity prior to inversion by dissolving the polymer into solution. This effectively lowers the time to intimately mix the water $(\mathrm{W})$ and oil-like polymer $(\mathrm{O})$ phases, forming a water-in-oil (W/O) emulsion prior to phase inversion [14]. The dispersion stage in SFEE generating the $\mathrm{W} / \mathrm{O}$ emulsion is strongly dependent on the mechanical energy imparted by the extruder to bring the two phases together intimately in the absence of solvent [7]. The timescale for maximizing interfacial area between the water and polymer phases is strongly influenced in both SE and SFEE by surface-active agents such as surfactants, and so the dispersion stage of SFEE can be better understood by perturbing the system with varying surfactants in comparison to SE where viscous effects are less prominent. It is believed that the highly viscous environment in the dispersion zone of SFEE retards surfactant migration to the $\mathrm{W} / \mathrm{O}$ interface being generated. To properly perturb the system, surfactants of both charged (ionic) and neutral (non-ionic) character should be investigated. Ionic surfactants have a charged hydrophilic head group and rely on head group repulsion to prevent unfavourable self-assembly, whereas non-ionic surfactants rely on the steric hindrance of their hydrophilic head 
groups $[1,15]$. There are advantages and disadvantages to using each type of surfactant. For example, non-ionic surfactants are less affected by electrolyte concentration in dilute aqueous solutions compared to their ionic counterparts whereas ionic surfactants are more effective particle stabilizers at lower molar concentrations and are far less sensitive to temperature [16]. In cases of both SE and SFEE, the sudden introduction of a large quantity of water destabilizes the W/O emulsion generated with surfactant(s), and due to the low osmotic pressure, the emulsion inverts into an $\mathrm{O} / \mathrm{W}$ emulsion to generate the much sought nanoparticles.

In this regard, the paper is seen as an examination of how surfactants with differing surfaceactive properties contribute to the mechanism of SFEE and how viscosity influences their effectiveness. Differences in particle size between solvent emulsification and solvent-free emulsification extrusion were used to study this mechanism whereas, a particle coalescence study was used to confirm that both processes produced particles with similar stability as a result.

\section{Materials and methods}

\subsection{Material}

A polyester synthesized from dipropoxylated bisphenol A and fumaric acid was supplied by Xerox Corporation (Webster, NY). The resin had a $\mathrm{T}_{\mathrm{g}}$ of approximately $60^{\circ} \mathrm{C}, \mathrm{M}_{\mathrm{W}}$ of 17,080 $\mathrm{g} / \mathrm{mol}\left(\mathrm{M}_{\mathrm{W}} / \mathrm{M}_{\mathrm{N}}=4.2\right)$, and acid number of $17.7 \pm 1.7 \mathrm{mg} / \mathrm{g} \mathrm{KOH}$. The anionic surfactant, 4dodecylbenzenesulfonic acid (SDBS) $\left(\mathrm{M}_{\mathrm{W}}=348.5 \mathrm{~g} / \mathrm{mol}\right)$, along with three non-ionic surfactants: Igepal CO-890 (polyoxyethylene nonylphenyl ether; $\mathrm{M}_{\mathrm{W}}=1982$ ), Brij 58 (polyethylene glycol hexadecyl ether; $\mathrm{M}_{\mathrm{W}}=1124$ ), Synperonic F-108 (polyethylene glycol-polypropylene glycolpolyethylene glycol triblock copolymer; $\mathrm{M}_{\mathrm{W}} \sim 14600 \mathrm{~g} / \mathrm{mol}$ ) were all purchased from SigmaAldrich. The anionic surfactant, Unicid 350 (long chain carboxylic acid; $\mathrm{M}_{\mathrm{w}}=340 \mathrm{~g} / \mathrm{mol}$ ) was donated by Baker Hughes (Houston, TX) and Calfax DB-45 (alkyldiphenyloxide disulfonate; 
$\mathrm{M}_{\mathrm{w}}=542 \mathrm{~g} / \mathrm{mol}$ ) was purchased from the Pilot Chemical Company (Cincinnati, OH); Calfax was the only surfactant supplied in liquid form as a $47 \mathrm{wt} \%$ aqueous solution. Sodium hydroxide $(\mathrm{NaOH})$ was purchased from Caledon Laboratories Ltd (Georgetown, ON, CA). Deionized MilliQ water was used in the preparation of all samples.

\subsection{Apparatus}

All extrusion experiments were done using a 27 mm 40 L/D Leistritz ZSE-HP co-rotating twin-screw extruder (American Leistritz Extruder Corporation; Somerville, NJ). The extruder barrel was comprised of a feed port (zone Z0) and nine heated zones (Z1-Z9), with a $15 \mathrm{~mm}$ bore diameter die at the outlet. The polyester granules were fed into the extruder at Z0 using a Brabender Technologie KT20 twin-screw gravimetric feeder (Mississauga, ON). Liquid injection sites were located at Z3 and Z7, connecting to a high-pressure Optos piston pump (41 MPa capacity) and a high-pressure syringe pump (51 MPa capacity) respectively. A layout of the process is shown in Fig. 1.

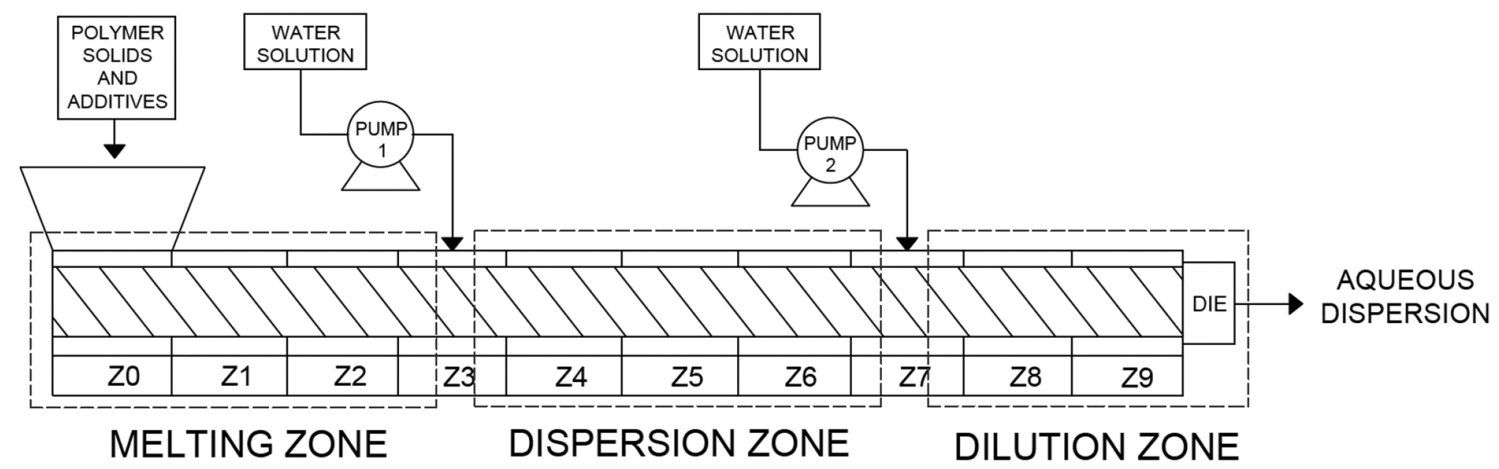

[Fig 1]

The bench scale coalescence trials were conducted using a custom-made $100 \mathrm{~mL}$ stainless steel vessel $(D=5.08 \mathrm{~cm}, \mathrm{~h}=50 \mathrm{~cm})$. A schematic representation of this vessel can be seen in Fig. 2, showing a cooling system and sampling port whereas heat and mixing were provided from a hot plate below the unit. Heat was provided by immersing the vessel up to its lid in silicone oil (rated 
for service up to $\left.140^{\circ} \mathrm{C}\right)$. Constant pressure $(270 \mathrm{kPa})$ was applied to prevent boiling inside the vessel but also assisted in sampling particles during trials without opening the unit. The apparatus was set up to collect samples reflecting the state of agglomeration inside with minimal chance to coalesce during their removal.

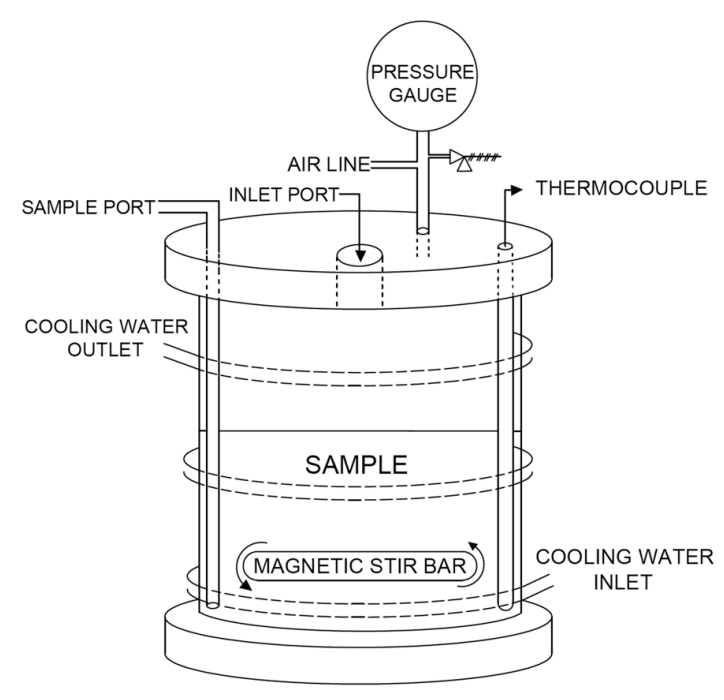

[Fig 2]

\subsection{Solvent Emulsification (SE)}

Polyester was dissolved in ethyl acetate in a glass vessel at a $1: 1.5$ weight ratio at $60^{\circ} \mathrm{C}$ under agitation with a stirrer. Methods for surfactant addition (at varied molecular loadings) were chosen based on their physical state; SDBS and Unicid 350 were dissolved directly with the polyester in the solvent, while the remainder of surfactants (Calfax, Igepal CO-890, Brij 58, Synperonic F-108) were added as aqueous solutions during the dispersion stage.

The dispersion stage involved the addition of an aqueous surfactant solution (if applicable), along with an alkaline solution containing $1 \%(\mathrm{w} / \mathrm{w}$ polymer) $\mathrm{NaOH}$ into the polymer solution, producing a $\mathrm{W} / \mathrm{O}$ emulsion with resultant resin/water $(\mathrm{R} / \mathrm{W})$ ratio of 3.5 (on a weight basis). The mixture was stirred for 5 minutes. For the dilution stage, phase inversion occurred by adjusting the $\mathrm{R} / \mathrm{W}$ ratio to 1.3 , followed by continually stirring the emulsion for an additional hour without heat. This emulsion was subsequently heated to $88^{\circ} \mathrm{C}$ for three hours to evaporate the ethyl acetate, 
aided by a low flow of blanketing nitrogen into the vessel. The complete procedure was based on Example 4 of US Patent 8,466,254 [17].

\subsection{Solvent-Free Extrusion Emulsification (SFEE)}

Extrusion trials were conducted at a uniform barrel temperature of $95^{\circ} \mathrm{C}$ and screw speed of 300 RPM. A constant feed rate for the resin was set at $8 \mathrm{~kg} / \mathrm{hr}$ for all experiments. The first injection site at zone $\mathrm{Z} 3$ represented the start of the dispersion stage, where the $\mathrm{R} / \mathrm{W}$ ratio was adjusted to 3.5 using a $1 \%$ (w/w resin) aqueous solution of $\mathrm{NaOH} ; \mathrm{NaOH}$ aided the function of the surfactants and converted over $50 \%$ of the end groups of the polyester into carboxylates to help water incorporation [7]. The second injection site at zone $\mathrm{Z7}$ corresponded to the start of the dilution stage, where the system was further adjusted to a $\mathrm{R} / \mathrm{W}$ ratio of 1.3 .

The surfactants being tested in these experiments were fed into the process by various methods. SDBS and Unicid 350 had to be fed into the process as dry blends with the polyester resin. Calfax was fed as a diluted solution together with aqueous $\mathrm{NaOH}$ at zone $\mathrm{Z} 3$. The feeding of Igepal CO-890 or Brij 58 was done using two different approaches (for reasons explained in a later section); both as a dry blend with the polyester or combination of dry blend and as a solution together with aqueous $\mathrm{NaOH}$. When fed as a solid, the surfactants were ground using a coffee grinder to break up lumps before being blended with the polyester by tumble mixing. When both Igepal CO-890 and Brij 58 were fed as solutions, they required dissolution in Milli-Q water at a raised temperature $\left(40^{\circ} \mathrm{C}\right)$ and constant agitation for 30 minutes prior to injection at zone $\mathrm{Z} 3$ along with $\mathrm{NaOH}$. Synperonic F-108 was never used in the SFEE process due to reasons discussed in a later section. A complete list of surfactant molar loadings used in both SE and SFEE processes can be seen in Table 1.

\subsection{Coalescence Study}


Emulsions prepared by both SE and SFEE were tested for their tendency to aggregate depending on temperature, agitation speed and $\mathrm{pH}$, examining conditions that might arise in the dilution stage of the twin screw extruder, using the previously described vessel immersed in an oil bath (Fig. 2). A constant emulsion volume of $30 \mathrm{~mL}$ was used for each experiment with $\sim 8 \%$ solids. The varied conditions included three temperatures $\left(60,90\right.$, and $\left.120^{\circ} \mathrm{C}\right)$, two stirrer speeds (100 and $400 \mathrm{RPM}$ ), and two $\mathrm{pH}$ values ( $\mathrm{pH} 7$ and 10); the emulsion $\mathrm{pH}$ was raised using $0.5 \mathrm{M}$ aqueous $\mathrm{NaOH}$. Each trial began once the temperature of the emulsion inside the vessel was $\pm 5^{\circ} \mathrm{C}$ of the setpoint temperature. The entire vessel was removed from the oil bath and quenched in an ice bath after 5 minutes \pm 10 seconds from the start of the trial. When the temperature inside the vessel reached $\sim 30^{\circ} \mathrm{C}$, the vessel was removed from the ice bath and a single sample of $\sim 15 \mathrm{ml}$ was collected at the sampling port.

\subsection{Characterization}

Prior to any characterization mentioned below, samples were triple filtered using a $35 \mu \mathrm{m}$ sieve to minimize any coarse particles present. Emulsified samples prepared by SE and SFEE were compared based on their particle size distributions, using two instruments. A NANOTRAC NPA250 dynamic light scattering particle size measurement system was capable of measuring particle sizes between 0.8 and $6500 \mathrm{~nm}$. A Mastersizer 2000 particle size measurement system was used for measuring particle sizes between 0.2 and $2000 \mu \mathrm{m}$. The combined results were reported based on three replicated measurements. To compare conditions in the coalescence tests where samples prepared by the different surfactants had significantly differing particle sizes, the span of the particle size distribution was the preferred measure to observe change. Span is a unitless value and is calculated from the difference in the mean volume diameter distribution moments, $\mathrm{D}_{10}$ and $\mathrm{D}_{90}$, and normalized by $\mathrm{D}_{50}$. 
Zeta potential results were obtained using the previously described NANOTRAC NPA 250 , calculated from four replicates. Images of selected samples by scanning electron microscopy (SEM) used a JEOL JSM-7000F electron microscope equipped with a Schottky Field emission gun.

Critical micelle concentration (CMC) for each surfactant was determined using a digital goniometer (First Ten Ångstroms) to analyze sessile drop contact angles. The method resembles the approach described by Chen [18]. At an ambient temperature of $25^{\circ} \mathrm{C}$, the contact angle was measured for a $10 \mu \mathrm{L}$ droplet of varied surfactant concentration placed on a compression molded sheet of the polyester. The droplet surfactant concentration was plotted versus contact angle, and the concentration value corresponding to the sharp change in the slope of the curve was taken as the $\mathrm{CMC}$ value for a surfactant. The statistical uncertainty for each respective characterization value described above has been summarized in Table 2 .

\section{Results}

\subsection{Surfactant Properties}

The anionic surfactants (SDBS, Unicid 350, and Calfax) and non-ionic surfactants (Igepal CO-890, Brij 58, Synperonic F-108) were all chosen based on their differing molecular structures and similar estimated HLB values. Each of the six surfactants had estimated HLB values larger than 8 , suitable for the stabilization of $\mathrm{O} / \mathrm{W}$ emulsions [19]. As chosen anionic surfactants, SDBS and Calfax had similar $\mathrm{C}_{12}$ alkyl chains (the only difference being their chain geometries) but different structures around their ionic functionality to affect their positioning at the interface and interaction with water. Unicid was a simpler, less hydrophilic anionic species with a longer nominal $\mathrm{C}_{21}$ alkyl chain and carboxylate head after saponification. The chosen non-ionics had alkyl chains varying in length close to $\mathrm{C}_{12}$ (with the exception of Synperonic) but varying oxyethylene 
chain lengths. In the case of non-ionics, they were felt to lay across the polyester boundary rather than protrude into the water phase due to their higher solubility in the oleic phase at elevated temperatures, making their ethoxy-based chain length important to their overall surface activity (Traube's Rule) [20]. A list of surfactant properties supplied by the vendors and the measured CMC values are given in Table 3. The molecular structures of the surfactants are shown in Fig. 3. Since very little work has been done in SFEE with these surfactants (with the exception of SDBS), the dissimilarities in these tested species allowed for a more intensive analysis on which types of molecules were more or less effective emulsifiers.

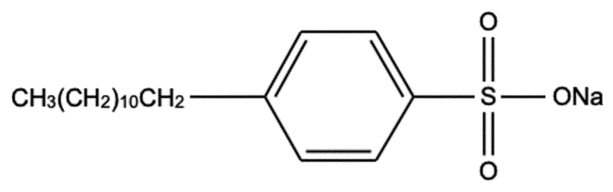

Sodium dodeclybenzene sulfate

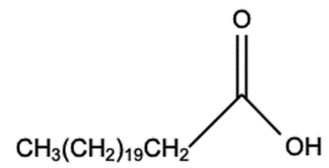

Unicid 350<smiles>CC(C)C(C)(C)C(C)(C)C(C)(C)c1ccc(Oc2ccc(S(C)(=O)=O)cc2)cc1[N+](=O)[O-]</smiles>

Calfax DB-45

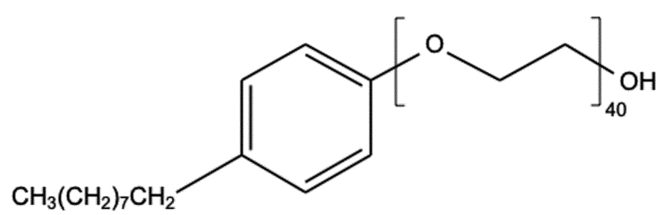

Igepal CO-890

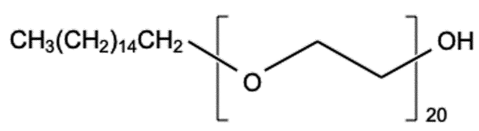

Brij 58

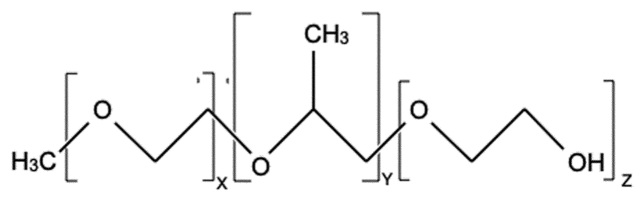

Synperonic F-108

[Fig. 3]

From the CMC values measured, it is seen that each tested surfactant, in both SE and SFEE trials, had the capacity to form micelles in the study; Unicid 350 was immiscible in water and so no CMC measurement was possible. There was a minor concern these chemical species might 
interfere with the particle size measurement. It was beyond the scope of this project to identify micelles in the systems studied but it was assumed they did not interfere in the results, accepting the analysis of others for both ionic and non-ionic surfactants where micelle diameters have been approximated to generally fall in the range of 2-20 $\mathrm{nm}$ [21-23] but to be less than $80 \mathrm{~nm}$ for even large macromolecular species like Synperonic F-108 [24]. Synperonic F-108 was included in the study to highlight the result of a poor surfactant's effectiveness on the two systems, SE versus SFEE.

\subsection{Anionic Surfactant with SE and SFEE Processes}

While comparing samples between SE and SFEE was ultimately intended in this study to gain new insights on viscous effects on emulsification in the extruder, the solvent method was also being tested as a screening tool for useful surfactants before use in the larger-scaled method of SFEE. Due to this latter consideration, the tests began at the bench scale using SE with the three chosen anionic surfactants. In this trial, SDBS was considered the baseline case due to earlier reported success with the species in SFEE [5-7]. Similarly, a surfactant loading of $0.22 \mathrm{mmol} / \mathrm{g}$ resin was considered the benchmark concentration since it was the concentration found in those same earlier SFEE studies to yield robust emulsification performance when other processing conditions were being varied. A summary of the representative moments for the mean $\left(D_{50}\right)$ and range of particle sizes $\left(D_{10}, D_{90}\right)$ in these samples with the three anionic surfactants is seen in Table 4, while the full particle size distributions at their best conditions are shown in Fig. 4 (a).

A monodisperse emulsion with particles predominantly in the $70-150 \mathrm{~nm}$ size range was produced with SDBS at the benchmark condition. The same surfactant loading with Unicid 350 yielded an emulsion with a slightly higher $\mathrm{D}_{50}$, along with some observable coarse generation in the 5-100 $\mu \mathrm{m}$ size range. The larger size fraction is not considered to be a result of Owstald 
ripening since the polymer has no solubility in the water phase and is generally attributed to inadequate stabilization by the surfactant [25]. Raising the surfactant loading of Unicid 350 did little to improve the resultant emulsion, therefore $0.22 \mathrm{mmol} / \mathrm{g}$ resin was considered to be its preferred loading in the SE process. Lowering the surfactant content of Unicid to $0.11 \mathrm{mmol} / \mathrm{g}$ resin proved disastrous with no emulsion evident (data not shown), whereas with SDBS the distribution only showed some broadening at this lower concentration but still the highest frequency of particles matched to the desired particle size. Replacing SDBS with Calfax at the benchmark condition of $0.22 \mathrm{mmol} / \mathrm{g}$ resin was seen to yield a nearly identical emulsion to the other two species. When the surfactant loading of Calfax was reduced to $0.11 \mathrm{mmol} / \mathrm{g}$ resin, no major changes in the final emulsion were seen. A further reduction in Calfax loading was seen to yield coarser particles though at $0.06 \mathrm{mmol} / \mathrm{g}$ resin, many of the produced particles were still acceptable. In summary, it was found that the benchmark concentration was suitable for SE with all tested anionic surfactants, and the order of preferred surfactants as emulsifiers for the system was Calfax $>$ SDBS $>$ Unicid 350 .

The SFEE results are summarized in Table 5 giving the representative distribution moments again, whereas full particle size distributions for the best condition of each surfactant are presented in Fig. 4 (b). At the benchmark condition of $0.22 \mathrm{mmol} / \mathrm{g}$ resin, SDBS was seen to result in a monodisperse emulsion having a $\mathrm{D}_{50}$ of $130 \mathrm{~nm}$, reproducing the results observed by $\mathrm{SE}$ as well as those SFEE findings published to date [5-7]. The direct translation of results at the benchmark condition between processes illustrates the robustness of SDBS in emulsifying polyester into nanometre sized particles, but the higher viscosity of the medium in SFEE does appear to require a critical concentration of the surfactant to diffuse to the interface at an appropriate rate corresponding to the residence time of the dispersion stage. For example, SDBS 
did not yield a satisfactorily emulsified product at the lower concentration of $0.11 \mathrm{mmol} / \mathrm{g}$ resin, unlike the findings by SE. Unicid 350 was far less successful in the SFEE process despite being added as a solid with the polyester in the same manner as SDBS. Unicid produced some coarse particles but the majority of resin exited as a W/O emulsion (euphemistically referred to as 'wet plastic') at the benchmark condition, needing to be increased to $0.52 \mathrm{mmol} / \mathrm{g}$ resin before emulsification was moderately successful; wet plastic looks like a shiny rod or rope of molten polymer exiting the extruder but shows no visibly separated water phase. At this higher Unicid concentration, the fraction of wet plastic decreased to $50 \%$ while the emulsified fraction had a higher than desirable particle size $\left(D_{50} \cong 400 \mathrm{~nm}\right)$ and contained a significant portion of coarse particles in the 10-500 $\mu \mathrm{m}$ range. No further increases in surfactant loading were tested for Unicid 350 , with the feeling that the concentration was getting unrealistically high for commercial use. At the benchmark condition, use of Calfax DB-45 produced very similar results to SE trials $\left(\mathrm{D}_{50} \cong\right.$ $160 \mathrm{~nm}$ ), with all of the polymer being emulsified successfully like SDBS. Decreasing surfactant loading to $0.13 \mathrm{mmol} / \mathrm{g}$ resin still achieved a successful emulsification, with a resulting $\mathrm{D}_{50}$ of 190 $\mathrm{nm}$. At the lowest concentration of $0.06 \mathrm{mmol} / \mathrm{g}$ resin, Calfax showed poor emulsification behaviour like SE, illustrated by the increase in measured coarse particles $\left(\mathrm{D}_{90}=3.90 \mu \mathrm{m}, \mathrm{Span}=\right.$ 12.3). In summary, the order of effective surfactants was the same between SFEE and SE, but a higher minimum concentration of anionic surfactant was required for SFEE. 

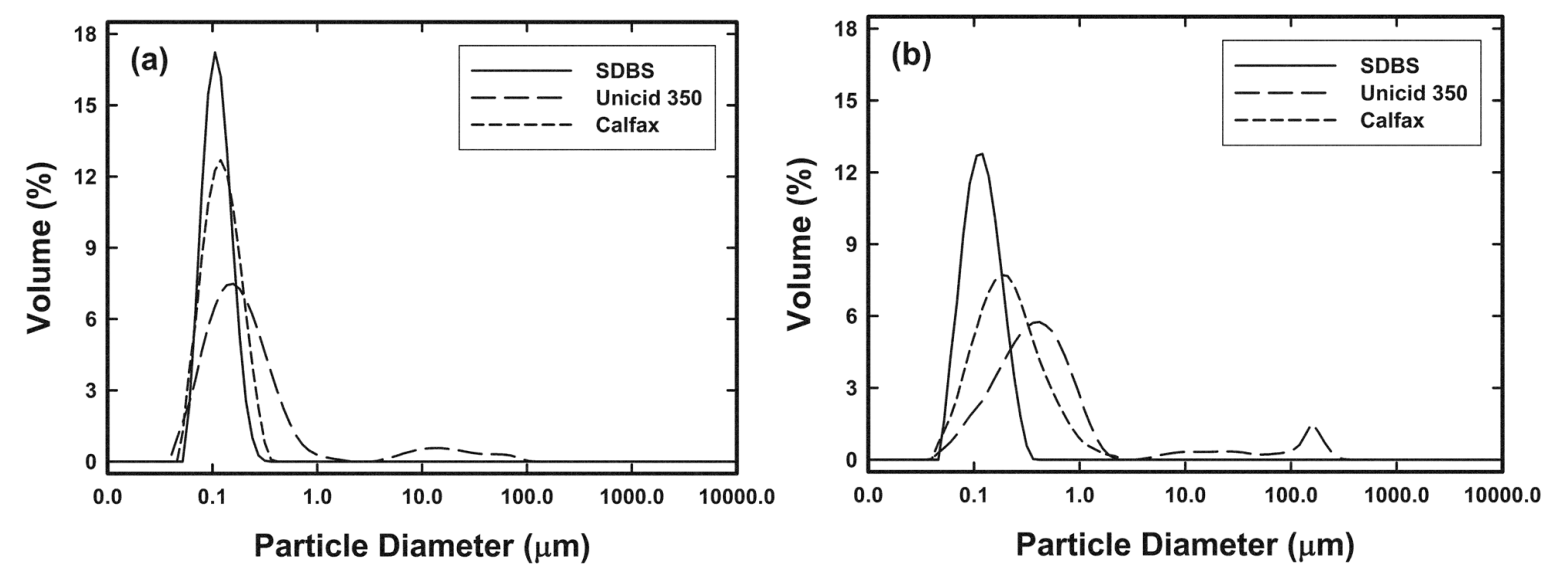

[Fig. 4 a-b]

\subsection{Non-ionic Surfactant with SE and SFEE Processes}

Following the same approach used with the anionic group, SE testing was conducted first using the selected non-ionic surfactants to determine a benchmark molar concentration for SFEE and determine their respective feasibility to aid emulsification of the polyester in water. A summary of the representative distribution moments for samples produced with the non-ionic surfactants by SE is given in Table 6 . The resulting particle size distributions for each non-ionic surfactant at its respectively preferred loading can be seen in Fig. 5 (a). The first surfactant tested in the SE process was Igepal CO-890 and after some variation in concentration, it was determined that a minimal loading of $0.11 \mathrm{mmol} / \mathrm{g}$ resin was necessary to achieve the desired goal. This concentration produced a monodisperse emulsion with a $\mathrm{D}_{50}$ of $120 \mathrm{~nm}$ and minimal coarse generated. A loading of $0.22 \mathrm{mmol} / \mathrm{g}$ resin performed equally well in achieving the desired nanoparticles, whereas a concentration of $0.04 \mathrm{mmol} / \mathrm{g}$ produced an unsatisfactory yield with too many coarse particles. This was an extremely positive finding since the effectiveness of non-ionics for SE compared to anionic species was not clear originally, but this outcome shows close equivalence in performance. A surfactant loading of $0.22 \mathrm{mmol} / \mathrm{g}$ resin was then tested with Brij 
58, producing an almost identical monodisperse emulsion to Igepal, and similarly, reducing the loading of Brij 58 below $0.11 \mathrm{mmol} / \mathrm{g}$ resin resulted in an increase in $\mathrm{D}_{50}$ and coarse particle generation. Synperonic F-108 was the last tested surfactant with SE and at $0.11 \mathrm{mmol} / \mathrm{g}$ resin, it was unsuccessful in creating a monodisperse emulsion. The lowest possible surfactant loading that resulted in nanoparticles with Synperonic F-108 was $0.22 \mathrm{mmol} / \mathrm{g}$ resin, which is an excessively large mass due to its high molecular weight. However, even at this concentration the resulting emulsion did not meet the desired particle size; the sample shows a tri-modal distribution with distinct peaks centered at approximately $250 \mathrm{~nm}, 2 \mu \mathrm{m}$, and $100 \mu \mathrm{m}$. Due to the high mass content, it was quite possible that a significant portion of the particles at $250 \mathrm{~nm}$ were micelles. Due to the poor and questionable results, Synperonic F-108 was rejected from further consideration beyond the SE trials. In summary, two non-ionic surfactants (Igepal CO-890 and Brij 58) were considered as possible candidates for SFEE with near-equal suitability, and apparently similar performance to anionic species by SE. It was decided to keep the benchmark condition the same for the non-ionic group $(0.22 \mathrm{mmol} / \mathrm{g}$ resin) even though $0.11 \mathrm{mmol} / \mathrm{g}$ resin was consistently the minimum concentration for SE since experience with extrusion in the anionic case had already shown that more surfactant is generally needed for SFEE.

The resulting particle size distributions for the two non-ionic surfactants in SFEE are seen in Fig. 5 (b) and their distribution moments are listed in Table 7. At the benchmark condition, Igepal CO-890 exhibited challenges related to feeding into the extruder. Igepal CO-890 is a waxy solid material, and feeding it in at even modest amounts through the hopper together with polyester resin resulted in bridging at the extruder inlet. Due to this blockage, it was not possible to introduce the full amount of Igepal CO-890 at $0.22 \mathrm{mmol} / \mathrm{g}$ resin by the feeder. To resolve this issue, approximately $12 \%$ of the total amount of Igepal was dissolved into the alkaline water and pumped 
into the extruder at zone $\mathrm{Z} 3$, with the rest of the surfactant being fed as a solid by the feeder. Looking at Fig. 5 (b), one can see that although the bulk of the particles are present in the 100$200 \mathrm{~nm}$ range, coarse particles in the range of $1-100 \mu \mathrm{m}$ were present. It is also important to note that only approximately $25 \%$ of the extrudate was emulsified material, with the rest being wet plastic. An increase in surfactant loading attempted to reduce the coarse particle generation, but increasing surfactant loading resulted in an unresolvable pumping issue related to the now higher viscosity of the aqueous solution at zone Z3. Looking at Brij 58, similar bridging issues were encountered that had to be resolved by dissolving $20 \%$ of the total surfactant into the injected alkaline solution at zone Z3. At $0.22 \mathrm{mmol}$ Brij $58 / \mathrm{g}$ resin, only about $5 \%$ of the solids were emulsified, having a $\mathrm{D}_{50}$ of $10 \mu \mathrm{m}$. Increasing the surfactant loading resulted in similar pumping issues of high solution viscosity seen with Igepal but at least in this case, a concentration of 0.32 $\mathrm{mmol} / \mathrm{g}$ Brij 58 was possible. At this higher concentration, the 5\% emulsified fraction exhibited a $\mathrm{D}_{50}$ decrease to $0.4 \mu \mathrm{m}$ but coarse particles as well $\left(\mathrm{D}_{90}=734 \mu \mathrm{m}\right)$, as seen by the distribution shown in Fig. 5 (b). The majority of the solids for both Igepal CO-890 and Brij 58 cases did not experience phase inversion, remaining as wet plastic. In summary, both non-ionic surfactants did poorly at testable conditions, even when fully introduced, though Igepal CO-890 emulsified more of the polyester compared to Brij 58 at the same concentration. Their performance in SFEE was not reflective of the SE results, which is markedly different from the anionic group. 

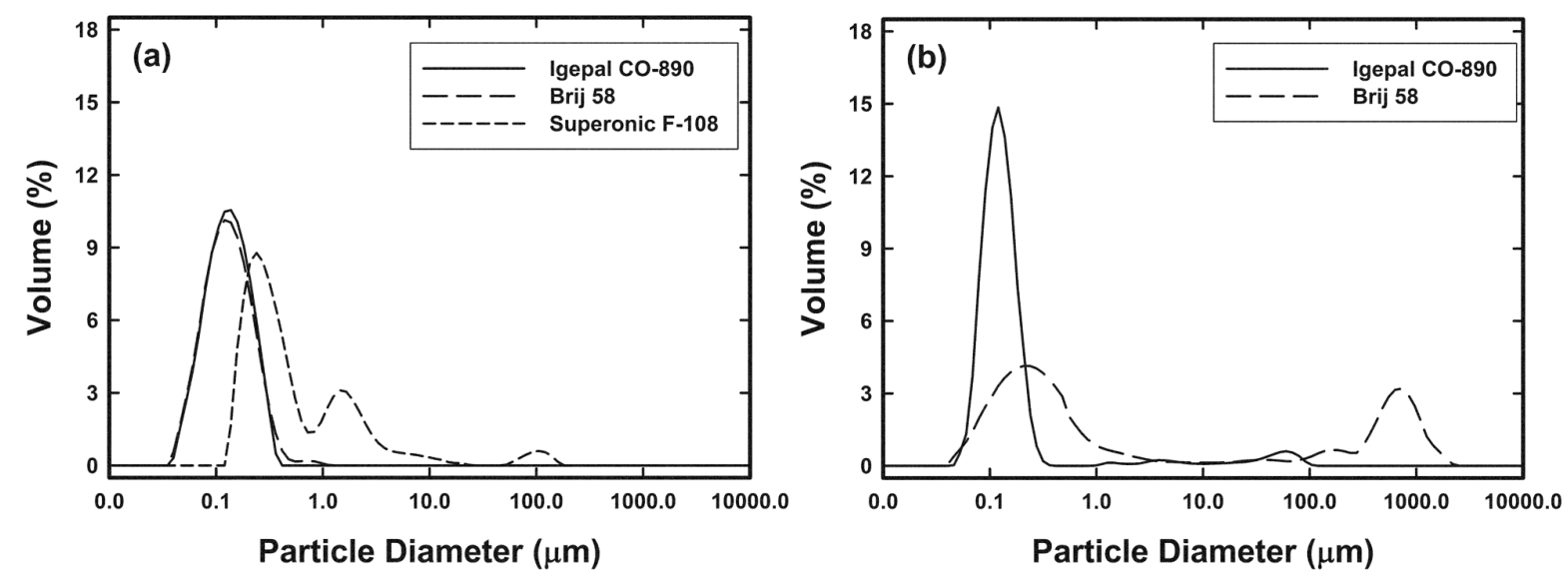

[Fig. 5 a-b]

\subsection{Particle Stability Examined by Zeta Potential and Coalescence Testing}

To ideally relate the differences seen by the surfactants between SE and SFEE to only the dispersion stage of the extruder, it was felt necessary to establish that the emulsion created by either method produced particles of similar stability; if the coarse particles seen are related to how the emulsions were generated rather than agglomeration after formation then the study could focus on just one stage of the SFEE process to explain the function of the surfactants. To examine particle stability, SE and SFEE O/W emulsions created with each of the previously described surfactants were tested at extremes (for the dilution stage) to determine which conditions (if any) would lead to particle de-stabilization. The complete set of aggregation results for each of the six surfactants can be seen in Fig. 6 (a-f). These figures illustrate destabilization by a change in the span of the particle size distribution since even the slightest increase in the volume percentage of coarse particles will impact this value and as a normalized value, it was better as a comparator between SE and SFEE. 
The overall stability of emulsions at 60 or $90^{\circ} \mathrm{C}$ and at $\mathrm{pH} 7$ or 10 , were considered excellent based on their negligible change in span, whether prepared by SE or SFEE. This observation was seen with all surfactants except Synperonic F-108 which was only made in the SE process. Looking at Fig. 6 (f), it can be seen that any emulsions produced with Synperonic F108 showed an increasing span and were deemed generally unstable. For the other surfactants, significant particle agglomeration was only detected for the samples at $120^{\circ} \mathrm{C}$ and $\mathrm{pH} 10$, seen for both SE and SFEE. Emulsions with any of the anionic and non-ionic surfactants showed no aggregation for any tested temperatures whenever the $\mathrm{pH}$ of the system was 7. Emulsions with Brij 58 were the only samples to never agglomerate at any condition in the tests.

The agglomeration observed at high $\mathrm{pH}$ is related to the increased overall ionic strength of the solution compressing the electrostatic double layer, which in turn reduced repulsive forces between particles [26]. Combined with temperatures far above the glass transition of the polyester $\left(60^{\circ} \mathrm{C}\right)$, it was not surprising that the particles approached close enough to aggregate at $120^{\circ} \mathrm{C}$ and $\mathrm{pH}$ 10. Fig. 7 presents SEM image of the sample at high $\mathrm{pH}$ and temperature $\left(120^{\circ} \mathrm{C}\right)$ with its particles sintered together, which is compared to an example of well separated particles at the same $\mathrm{pH}$ yet $90^{\circ} \mathrm{C}$. This instability in agglomerated samples was also quantitatively observed by their measured zeta potential values. The closer the measured zeta potential was to zero, the less stable the suspension. The zeta potential values for both the SE and SFEE samples can be seen in Tables 8 and 9, respectively. The samples with anionic surfactants ranged in zeta potential from $-30 \mathrm{mV}$ to $-50 \mathrm{mV}$ at neutral $\mathrm{pH}$ and $60^{\circ} \mathrm{C}$, while those with non-ionic surfactant ranged from $-15 \mathrm{mV}$ to $25 \mathrm{mV}$; the non-zero zeta potential for non-ionic species is not uncommon in studies [19] and often relates to contaminants, which in this case should be the sodium carboxylate polyester end groups. The tables illustrate changes in zeta potentials for emulsions that had been coalesced at 60 or $120^{\circ} \mathrm{C}$ 
for both $\mathrm{pH}$ conditions. Looking at these results, one can see similar trends in sample instability to those observed in Fig. 6. No large drops in zeta potential were observed for any of the surfactants at $\mathrm{pH} 7$ (with the exception of Igepal CO-890) regardless of preparation technique. When looking at the values measured at $\mathrm{pH} 10$, almost all of the tested surfactants were seen to experience a significant change in zeta potential as conditions shifted from 60 to $120^{\circ} \mathrm{C}$, reflecting the overall emulsion instability seen with particle size measurements. Overall, the emulsions prepared with both SE and SFEE exhibited similar trends in measured zeta potential over the tested conditions.
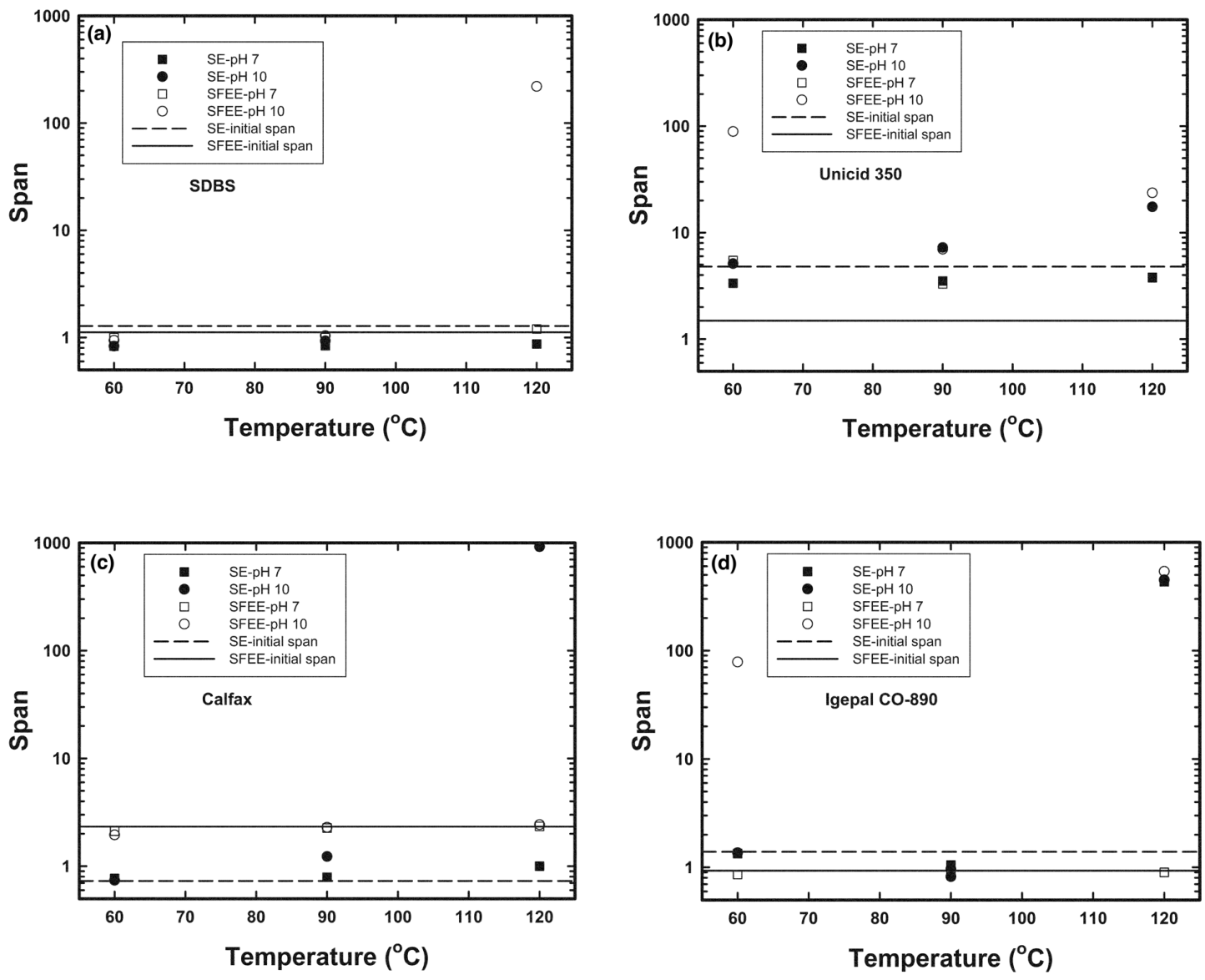

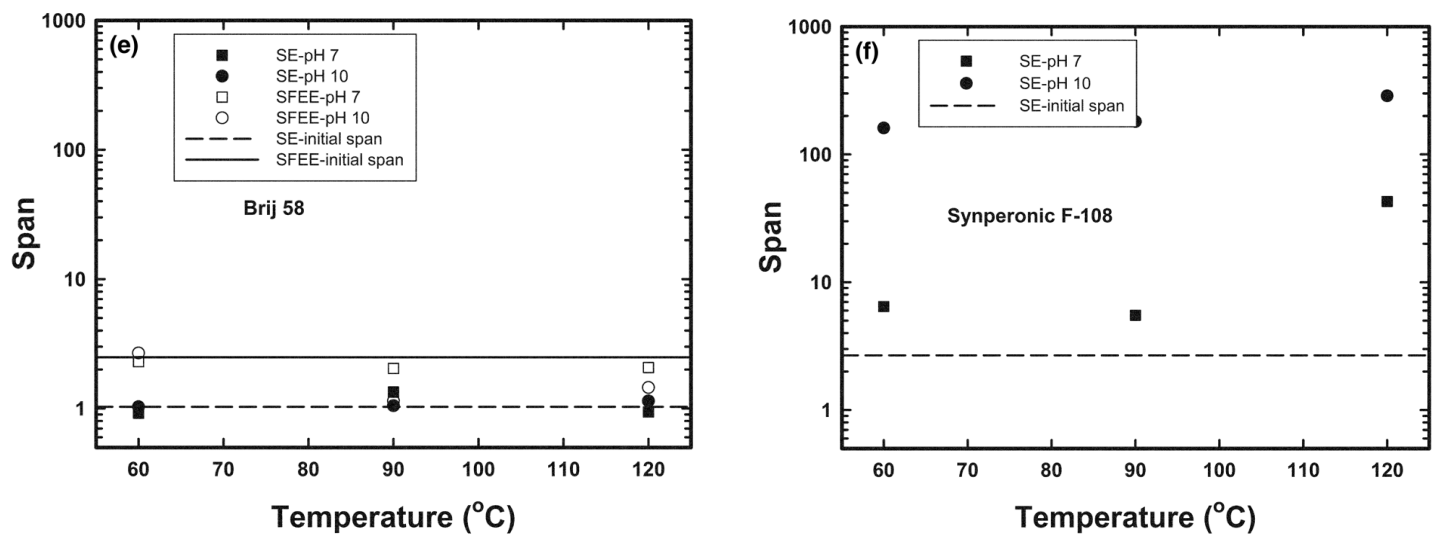

[Fig. 6 a-f]

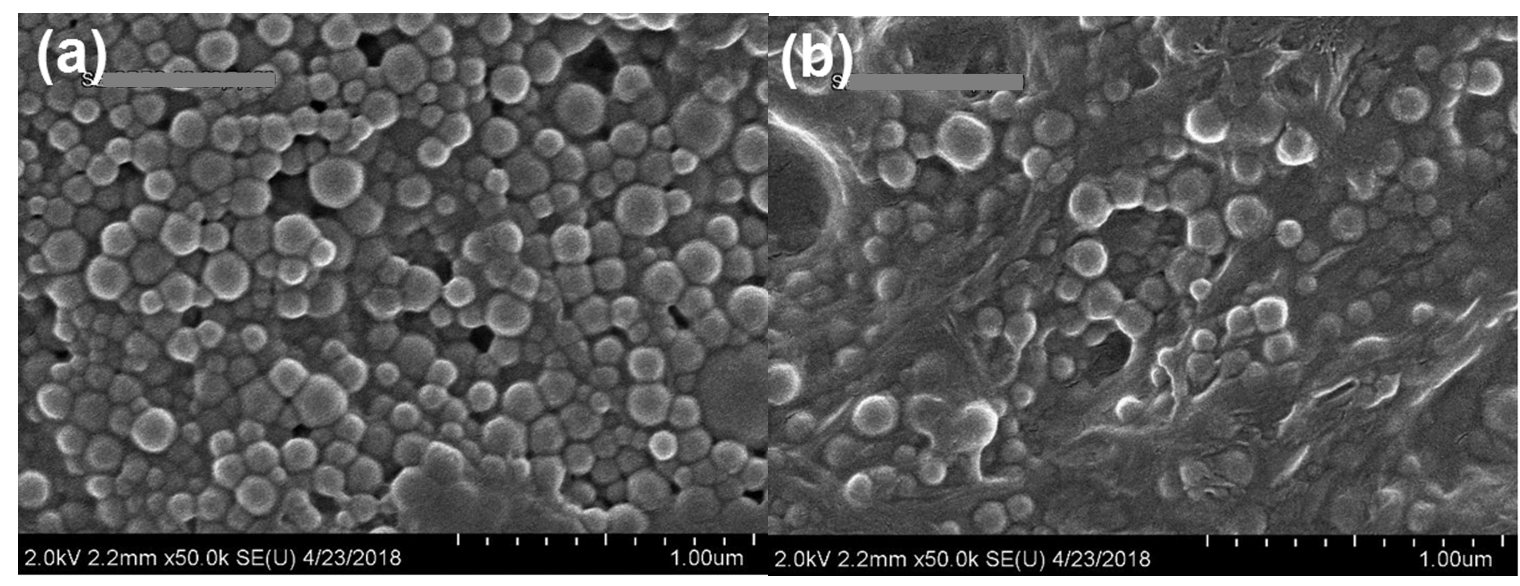

[Fig. 7 a-b]

\section{Discussion}

Prior to discussing the contribution of surfactants in SFEE, it should be recognized that an important function of the added $\mathrm{NaOH}$ was to functionalize the end groups of polyester chains, lowering the interfacial tension and promoting water incorporation. In the absence of surfactant, these created anionic carboxylate groups have only minor effectiveness in emulsification, with demonstrated particles as small as $1.3 \mu \mathrm{m}[5-7,13]$ but never yielding sub-micron sizes. The rate of this reaction is notably improved by the presence of a surfactant [7]; the influential contributions 
of surface-active species to the described functionalization above, has been studied elsewhere [28]. With the addition of surfactant, a more evolved, thinner lamellae phase morphology is possible prior to phase inversion, which is considered necessary to generate the desired particle size by SFEE. Previous studies have related the thickness of striated lamella in the shear field of the extruder, prior to phase inversion, to the final particle size for SFEE [14]. Without the successful generation of the W/O lamellae morphology, the subsequent creation of nano-sized particles is improbable, making the function of surfactants in the dispersion stage critical for this process.

\subsection{Anionic Surfactant Performance}

The anionic and non-ionic surface active species chosen had HLB values intended to drive the system to produce stable $\mathrm{O} / \mathrm{W}$ emulsions by the dilution stage, though both $\mathrm{W} / \mathrm{O}$ and $\mathrm{O} / \mathrm{W}$ emulsions were produced in this study based on surfactant performance. Their performance for the limited residence time of the process was dependent on their chemical functionality but also foreseeably affected by the manner of their introduction into the system; surfactant migration to the interface from the oleic phase was assumed to be more significantly impeded, at least initially, in SFEE due to restricted mobility with an oil-phase measured viscosity of 230 Pa-s versus 0.66 Pa-s for SE (at process temperature). As discussed below, this appeared to be a reasonable assumption, though definitive proof was challenging since chemical functionality and the molar mass of a species are inter-related, just as droplet dispersion is related to both convective mixing and interfacial forces. The physical properties of each surfactant determined the manner by which it was added, whether in the oil phase or aqueous phase, for both emulsification methods while SFEE imposed further constraints on its addition compared to SE. Since coalescence testing was helpful in showing the particles were all similarly stabilized once formed, irrespective of the surfactant used, we assume the different particle size distributions observed reflected the migration 
of the active species from one phase to the interface which had been retarded or aided by the difference in oleic phase viscosity.

The anionic species covered the range of HLB values relevant to producing an $\mathrm{O} / \mathrm{W}$ emulsion but also, unintentionally, covered the three main methods of incorporating emulsifying agents [29]. Unicid 350 was added by the nascent soap method (fatty acid added to the oleic phase while the alkaline reactant was present in the water phase). The poor performance of Unicid 350 as an anionic surfactant compared to the other two species can be partially attributed to this method of addition as well as its HLB value. Using the nascent soap method creates a mixing constraint on water incorporation by the fact that forming the $\mathrm{W} / \mathrm{O}$ emulsion is kinetically controlled by the neutralization reaction which will be rate-limited to interfacial area growth between the phases so that Unicid and $\mathrm{NaOH}$ can access one another. The fact that this surfactant's effectiveness was more strongly affected by the oleic phase viscosity (comparing SE versus SFEE results) points to this rate-limitation being a significant factor; at least $140 \%$ more Unicid was needed to get reasonably sized particles in SFEE compared to SE whereas only $100 \%$ more SDBS or Calfax accomplished the same goal. The limited effectiveness of the carboxylated end groups of the polyester in interfacial growth has been similarly attributed to their slow neutralization reaction in the bulk phase of SFEE in previous studies [7]. The second issue for Unicid 350 was its low HLB value (attributed to its longer lipophilic group), meaning it will exhibit a lower tendency to drive inversion of the $\mathrm{W} / \mathrm{O}$ emulsion formed in the dispersion stage upon the second addition of water. The lack of a phenyl group also likely hindered the effectiveness of Unicid in SFEE, where the phenyl rings present in both SDBS and Calfax contribute significantly to their steric stabilization abilities. To overcome these issues, much higher molar loadings of Unicid 350 were required $(0.52$ 
$\mathrm{mmol} / \mathrm{g}$ resin) to achieve the same stabilization in SFEE compared to Calfax $(0.11 \mathrm{mmol} / \mathrm{g}$ resin $)$ or SDBS (0.22 $\mathrm{mmol} / \mathrm{g}$ resin).

Neither Calfax nor SDBS were dependent on their neutralization in the process like Unicid and so, both were considered immediately effective for water incorporation into the oleic phase. SDBS was added by the agent-in-oil method while Calfax was added by the agent-in-water method [29]. Both SDBS and Calfax needed 100\% more content in SFEE versus SE and that observation diminished concerns that surfactant mobility was a rate-limiting effect on interfacial growth of the W/O system; the higher amount of Calfax should not have been needed in SFEE versus SE had its mobility been the controlling factor in emulsification since the water phase viscosity did not notably differ between the two methods whereas a comparatively larger increase in SDBS should have been necessary to accommodate the 350 time increase in viscosity for the oleic phase in SFEE versus SE. Rather, the rate-limitations imposed on lamellae formation and thinning by phase viscosity was considered the primary cause for the necessary increase in surfactant content between SFEE versus SE. The high HLB value of Calfax was felt to explain its improved performance compared to SDBS, thus needing a lower concentration for phase inversion; possessing disulfonated groups increased the affinity of Calfax to draw water into the oleic phase. Adding SDBS into the process as a dry blend with polyester resin did present concerns initially over its homogeneity in the melt but comparing its performance in both processes versus Calfax (which would not be expected to have dispersion concerns in the water phase), the results do not support this factor as a reason for the difference in particle size between SE and SFEE.

Overall, the results with the anionic species show the importance of the surfactant to provide immediate performance in the short residence time of the dispersion stage. However, phase viscosity only appeared to affect the neutralization reaction, not a species' capacity to participate 
in interfacial growth. This is perhaps related to their relatively small molar mass and strong driving tendency to incorporate water that brings them to the interface so readily, and it has been shown that their overall effectiveness in driving interfacial growth between the water and polymeric phases depends on their unique physio-chemical characteristics. Oleic phase viscosity will certainly affect mixing of the two phases in the dispersion stage, being seen when comparing SE versus SFEE as well as in previous results of SFEE where the melt viscosity was purposefully altered [5].

\subsection{Non-Ionic Surfactant Performance}

Non-ionic surfactants can be used alone to impart steric stabilization and decrease interfacial tension, though they are primarily considered more beneficial as auxiliary surfactants to ionic species [30,31]. The effectiveness of tested non-ionic surfactants was more strongly dependent on the PIE method than seen with the anionic species. In SE, Igepal and Brij were just as effective as SDBS in achieving the desired particle size, due in part to their HLB values being similar; Synperonic was never effective for SE and this can be ascribed to its weaker affinity with the oleic phase compared to the others since it lacks an alkyl chain end. Based on these results, both Igepal and Brij were considered to have the chemical affinity to drive our polyester system to an $\mathrm{O} / \mathrm{W}$ emulsion. Despite this claim, Igepal and Brij were both incapable of inducing significant phase inversion in the highly viscous SFEE process, with more than $75 \%$ of the polyester remaining as a $\mathrm{W} / \mathrm{O}$ emulsion by the exit of the extruder. The higher system temperature with SFEE may have increased the affinity of these non-ionic species for the oleic phase rather than water phase which reduced their effectiveness for driving phase inversion [32]. However, the temperature difference $\left(35^{\circ} \mathrm{C}\right)$ should be considered minor between SE and SFEE processes, making it difficult to ascribe temperature-dependent solubility issues as fully explaining the 
differences seen in emulsification performance compared to viscosity effects. Rather, if we reflected on the fact that Igepal with its higher HLB and CMC values emulsified more of the polyester than Brij but also reflected on the previous anionic results, it seems appropriate to claim that the selection of an effective surfactant in SFEE relies significantly on whether it possesses a high enough affinity for water to overcome retarding viscous forces affecting its migration to the interface. Both of the non-ionic species tested were deemed to lack high enough affinity for water to compensate for the high melt viscosity, effectively incapable of driving interfacial growth during mixing in the dispersive stage with this polyester/water system. It is pointed out that this finding is specific to the kinetics of mixing and generation of interfacial area, not necessarily to migration within a specific phase. Migration in a specific phase could not be studied in this work since the two non-ionics (Igepal and Brij) needed to be employed by both agent-in-water and agent-in-oil addition methods simultaneously.

Our results showed a slight improvement in emulsification characteristics with Igepal compared to Brij, as mentioned above. Surfactants with shorter, bulky end groups like Igepal seem to exhibit greater extension across the two phases than species like Brij. The increased hydrodynamic radius of Igepal caused it to orient more-or-less perpendicularly at the interface due to steric reasons while species like Brij are more likely to lay across the interface [33].

Overall, the results with the non-ionic species are showing their ineffectiveness as sole emulsifiers in the SFEE process. The positive results obtained in SE did not translate to SFEE (similarly to that which was previously seen with Unicid 350), an indication to the inability of these non-ionic surfactants to overcome the high phase viscosity ratio present in SFEE within the short residence time in the dispersion stage. This is believed to be a combination of their weak affinity to water, and their increased adsorption to the oleic phase with the high temperatures 
present in SFEE. Increasing molar concentration would likely improve the overall performance of the non-ionic surfactants but the physical limitations associated with their loading into the extruder makes this difficult to determine as true.

\section{Conclusion}

The higher phase viscosity of the oleic phase typical of SFEE presents a major challenge for the considered surfactants. The findings of this study indicate that the chemical affinity of the surfactant towards water must increase in compensation for the retarding viscous forces opposing interfacial generations during mixing in the dispersion stage of the PIE process. In this study, only Calfax exhibited sufficient water affinity to not require an increase in its molar concentration for stable SFEE operation compared to SE. SDBS required a $100 \%$ increase in molar concentration from SE, while Unicid 350 was found to be ineffective in SFEE at practical surfactant loadings. Neither of the two non-ionics were capable of completely inducing phase inversion in the SFEE process, with over $75 \%$ of the extruded solids made with either surfactant bound as a W/O emulsion rather than phase inverting. Igepal was seen to slightly outperform Brij in SFEE; the slightly higher HLB value and higher CMC value related to its bulky hydrophobic end group are believed to be the reason. Future studies selecting more highly water soluble non-ionic species should avoid the issues seen in the present study regarding their addition, allowing for a better assessment on the relevance of surfactant location on their ultimate performance. The results of this study bring new insight into the relationship between surfactant surface chemistry and PIE phase viscosity. This understanding is beneficial in choosing appropriate mixtures of surfactants for our subsequent studies seeking to lower surface charge in nanoparticles generated by SFEE.

\section{Acknowledgements}


The authors wish to thank the Natural Sciences and Engineering Research Council of Canada (NSERC) for its funding of this work. In addition, we wish to express our appreciation to the Xerox Corporation and Xerox Research Centre of Canada for the materials and expertise provided to the project. Finally, the authors would also like to thank the Canadian Centre of Electron Microscopy for use of their facility.

\section{References}

1. F. Leal-Calderon, V. Schmitt, J. Bibette, Emulsion Science - Basic Principles, Springer, New York, NY 2007. https://doi.org/10.1007/3-540-70820-0.

2. M. Trotta, F. Debernardi, O. Caputo, Int. J. Pharm. 2003, 257, 153. https://doi.org/10.1016/s0378-5173(03)00135-2.

3. H. Murakami, M. Kobayashi, H. Takeuchi, Y. Kawashima, Int. J. Pharm. 1999, 187, 143. https://doi.org/10.1016/s0378-5173(99)00187-8.

4. R.H. Staff, D. Schaeffel, A. Turshatov, D. Donadio, H. Butt, K. Landfester, K. Koynov, D. Crespy, Small 2013, 20, 3514. https://doi.org/10.1002/smll.201300372.

5. A. Goger, M.R. Thompson, J.L. Pawlak, M.A. Arnould, A. Klymachyov, R. Sheppard, D.J.W. Lawton, Poly. Eng. And Sci. 2017, 58, 775. https://doi.org/10.1002/pen.24613.

6. A. Goger, M.R. Thompson, J.L. Pawlak, M.A. Arnould, D.J.W. Lawton, Ind. Eng. Chem. Res. 2018, 57, 12071. https://doi.org/10.1021/acs.iecr.8b02649.

7. A. Goger, M.R. Thompson, J.L. Pawlak, M.A. Arnould, D.J.W. Lawton, AIChE J. 2017, 64, 2113. https://doi.org/10.1002/aic.16066.

8. R.A. Lundgard, J.E. Pate III, C. Piechocki, P.T. Keillor III, N.E. Lutenske, I. Thumma (Dow Global Tech. LLC), U.S. 6,512,024, 2003.

9. K. Nakamichi, S. Izumi, \& H. Yasuura (Nippon Shinyaku Co., Ltd.), U.S. 5,456,923, 1995. 
10. Y. Doi, R. Ishioka, Y. Okino, M. Imaizumi (Showa Denko KK.), U.S. 6,716,911, 2004.

11. G. Koehler, J. Schmidt-Thuemmes, N. Hasenbein, L. Schlemmer, W. Dietsche (BASF), U.S. 4,996,259, 1991.

12. M.A.A.M. Koenraadt, G.H. Beijers, J.E. Borgstrom, K.R. Sorensen (Akso Nobel NV.), U.S. 6,812,269, 2004.

13. S. Faucher, J. T. Chung, T.L. Lincoln, S. Qiu, Y. Tong, F. Higuchi, E.I. Serifoglu, A.K. Chen, B.J. Andaya, J.L. Leonardo (Xerox Corp.), U.S. 8,618,192, 2009.

14. D.J.W. Lawton, Master Thesis, McMaster University 2013.

15. L. Uppgard, PhD Thesis, Umeå University 2002.

16. C.E. Stevens, J. Am. Oil Chem. 'Soc. 1957, 32, 182. https://doi.org/10.1007/bf02670948.

17. G.G. Sacripante (Xerox Corp.), U.S. 8,466,254B2, 2009.

18. L. Chen, S. Lin, C. Huang, E. Chen, Colloids Surf A. 1998, 13, 175. https://doi.org/ 10.1016/s0927-7757(97)00238-0.

19. J. Boyd, C. Parkinson, P. Sherman, J. Colloid Interface Sci. 1972, 41, 359. https://doi.org/ $10.1016 / 0021-9797(72) 90122-1$.

20. A.F.H. Ward, J. Chem. Soc. Faraday Trans. 1946, 42, 399. https://doi.org/ $10.1039 /$ tf9464200399.

21. R.J. Robson, E.A. Dennis, J. Phys. Chem. 1977, 81, 1075. https://doi.org/ $10.1021 / \mathrm{j} 100526 \mathrm{a} 010$.

22. C. Tanford, J. Phys. Chem. 1972, 76, 3020. https://doi.org/10.1021/j100665a018.

23. D. Stigter, J. Phys. Chem. 1974, 78, 2480. https://doi.org/10.1021/j100617a013.

24. D. Attwood, J.H Collett, C.J. Tait, Int. J. Pharm. 1985, 26, 25. https://doi.org/10.1016/03785173(85)90197-8. 
25. D.L. Tillier, J. Meuldijk, C. E. Koning, Polymer. 2003, 44, 7883. https:// doi.org/10.1016/j.polymer.2003.10.052

26. S.H. Behrens, D.I. Christl, R. Emmerzael, P. Schurtenberger, M. Borkovec, Langmuir. 2000, 16, 2566. https://doi.org/10.1021/la991154z.

27. R.A. French, A.R. Jacobson, B. Kim, S.L Isley, R. Lee Penn, P.C. Baveye, Environ. Sci. Tech. 2009, 43, 1354. https://doi.org/10.1021/es802628n.

28. R.J. Smith, M. Lotya, J.N. Coleman, New J. Phys. 2010, 12, 125008. https://doi.org/ $10.1088 / 1367-2630 / 12 / 12 / 125008$.

29. B. Samiey, C.H. Cheng, J. Wu, J. Chem. 2014, 2014, 1. https://doi.org/ $10.1155 / 2014 / 908476$.

30. P. Becher, Emulsions: Theory and Practice, Reinhold Publishing Corp., New York, NY 1959. https://doi.org/10.1002/app.1959.070020424.

31. C. Chern, F. Lin, J. Macro. Sci. 1996, 33, 1077. https://doi.org/ $10.1080 / 10601329608010906$.

32. H. Chu, I. Piirma, Polym. Bull. 1989, 21, 301. https://doi.org/10.1007/bf00955922.

33. K. Steinby, R. Silveston, B. Kronberg, J. Colloid Interface Sci. 1993, 155, 70. https://doi.org/10.1006/jcis.1993.1011.

34. J. Zhao, W. Brown, J. Phys. Chem. 1996, 100, 3775. https://doi.org/10.1021/jp952744i.

\section{Figure Captions}

Fig. 1. Schematic representation of the SFEE process inside a twin-screw extruder. 
Fig. 2. Schematic drawing of aggregation testing vessel.

Fig. 3. Molecular structures for the six surfactants tested in this study.

Fig. 4. a) Particle size distribution results for SE emulsions with surfactant loadings of: SDBS and Unicid 350 at $0.22 \mathrm{mmol} / \mathrm{g}$ resin, and Calfax at $0.11 \mathrm{mmol} / \mathrm{g}$ resin. b) Particle size distribution results for SFEE emulsions with surfactant loadings of: SDBS at $0.22 \mathrm{mmol} / \mathrm{g}$ resin, Unicid 350 at $0.52 \mathrm{mmol} / \mathrm{g}$ resin, and Calfax at $0.13 \mathrm{mmol} / \mathrm{g}$ resin.

Fig. 5. a) Particle size distribution results for SE emulsions with surfactant loadings of: Igepal CO890 and Brij 58 at $0.11 \mathrm{mmol} / \mathrm{g}$ resin, and Synperonic F-108 at $0.22 \mathrm{mmol} / \mathrm{g}$ resin. b) Particle size distribution results for SFEE emulsions with surfactant loadings of: Igepal CO-890 at $0.22 \mathrm{mmol} / \mathrm{g}$ resin and Brij 58 at $0.32 \mathrm{mmol} / \mathrm{g}$ resin.

Fig. 6. Aggregation data for both $\mathrm{SE}$ and SFEE samples tested at various $\mathrm{pH}$ values, and temperatures for six different surfactants at their respective molar loadings: a) SDBS [SE \& SFEE: $0.22 \mathrm{mmol} / \mathrm{g} \mathrm{resin}$ ], b) Unicid 350 [SE: 0.22 $\mathrm{mmol} / \mathrm{g}$ resin, SFEE: 0.52mmol/g resin], c) Calfax [SE: $0.11 \mathrm{mmol} / \mathrm{g}$ resin, SFEE: $0.13 \mathrm{mmol} / \mathrm{g} \mathrm{resin}$ ], d) Igepal CO-890 [SE \& SFEE: $0.22 \mathrm{mmol} / \mathrm{g}$ resin], e) Brij 58 [SE \& SFEE: $0.22 \mathrm{mmol} / \mathrm{g}$ resin], f) Synperonic F-108 [SE: $0.22 \mathrm{mmol} / \mathrm{g}$ resin].

Fig. 7. SEM images comparing results of SE emulsions tested with SDBS at pH 10 and a) $90^{\circ} \mathrm{C}$, and b) $120^{\circ} \mathrm{C}$. 


\section{Tables}

\section{Table 1}

Range of surfactant molar loadings used in both SE and SFEE experimentation

\begin{tabular}{|c|c|c|c|c|c|c|c|c|}
\hline \multirow{3}{*}{ Surfactant } & \multicolumn{4}{|c|}{ Solvent Emulsification } & \multicolumn{4}{|c|}{$\begin{array}{c}\text { Solvent-Free Extrusion } \\
\text { Emulsification }\end{array}$} \\
\hline & \multicolumn{2}{|c|}{$\begin{array}{c}\text { Range of } \\
\text { Surfactant } \\
\text { Weight } \\
\text { Fractions [pph] }\end{array}$} & \multicolumn{2}{|c|}{$\begin{array}{l}\text { Range of Molar } \\
\text { Loadings } \\
\text { [mmol/g Resin] }\end{array}$} & \multicolumn{2}{|c|}{$\begin{array}{c}\text { Range of } \\
\text { Surfactant } \\
\text { Weight } \\
\text { Fractions [pph] }\end{array}$} & \multicolumn{2}{|c|}{$\begin{array}{l}\text { Range of Molar } \\
\text { Loadings } \\
\text { [mmol/g Resin] }\end{array}$} \\
\hline & Min. & Max. & Min. & Max. & Min. & Max. & Min. & Max. \\
\hline SDBS & 3.6 & 7.5 & 0.10 & 0.22 & 4 & 7.5 & 0.11 & 0.22 \\
\hline Unicid 350 & 7.5 & 16 & 0.10 & 0.44 & 8.1 & 17.7 & 0.22 & 0.52 \\
\hline Calfax & 7.1 & 24 & 0.06 & 0.22 & 2.4 & 12 & 0.04 & 0.22 \\
\hline Igepal CO-890 & 7.5 & 86 & 0.04 & 0.44 & 20.3 & 41.7 & 0.11 & 0.22 \\
\hline Brij 58 & 7.5 & 48 & 0.07 & 0.44 & 24.2 & 35.2 & 0.22 & 0.32 \\
\hline Synperonic F-108 & 7.5 & 313 & 0.01 & 0.22 & & & & \\
\hline
\end{tabular}

\section{Table 2}

Relative standard error values for the different characterization parameters presented.

\begin{tabular}{|c|c|}
\hline Parameter & $\begin{array}{c}\text { Average Relative Standard } \\
\text { Errors }\end{array}$ \\
\hline D $_{50}$ & $\pm 0.02 \mu \mathrm{m}$ \\
\hline Span & $\pm 0.05 \mu \mathrm{m}$ \\
\hline Zeta Potential & $\pm 3.00 \mathrm{mV}$ \\
\hline CMC & $\pm 0.01 \mathrm{mM}$ \\
\hline
\end{tabular}

Table 3

Selected surfactant physical and chemical properties

\begin{tabular}{|c|c|c|c|c|c|}
\hline Name & Surfactant Type & Physical State & $\begin{array}{c}\text { Molecular } \\
\text { Weight }[\mathrm{g} / \mathrm{mol}]\end{array}$ & HLB & $\begin{array}{c}\text { CMC } \\
{[\mathrm{mM}]}\end{array}$ \\
\hline SDBS & Anionic & Solid & 348.5 & 10.6 & 1.2 \\
\hline Unicid 350 & Anionic & Solid & 340 & 8.9 & N/A \\
\hline Calfax DB-45 & Anionic & Liquid & 542 & 17 & 1.04 \\
\hline Igepal CO-890 & Non-Ionic & Solid & 1982.5 & 18 & 0.27 \\
\hline Brij 58 & Non-Ionic & Solid & 1122 & 15.7 & 0.06 \\
\hline Synperonic F-108 & Non-Ionic & Solid & $\sim 14600$ & $>20$ & 1.89 \\
\hline
\end{tabular}




\section{Table 4}

Particle size summary for anionic surfactant based emulsions created using SE.

\begin{tabular}{|c|c|c|c|c|c|c|}
\hline Surfactant & $\begin{array}{c}\text { Surfactant } \\
\text { Amount } \\
{[\mathrm{pph}]}\end{array}$ & $\begin{array}{c}\text { Surfactant Loading } \\
{[\mathrm{mmol} / \mathrm{g} \text { resin }]}\end{array}$ & $\begin{array}{c}\mathrm{D}_{10} \\
{[\mu \mathrm{m}]}\end{array}$ & $\begin{array}{c}\mathrm{D}_{50} \\
{[\mu \mathrm{m}]}\end{array}$ & $\begin{array}{c}\mathrm{D}_{90} \\
{[\mu \mathrm{m}]}\end{array}$ & Span \\
\hline SDBS & 7.5 & 0.22 & 0.07 & 0.10 & 0.15 & 1.36 \\
\hline SDBS & 3.6 & 0.11 & 0.07 & 0.12 & 0.23 & 1.35 \\
\hline Unicid 350 & 15 & 0.44 & 0.08 & 0.20 & 0.59 & 2.55 \\
\hline Unicid 350 & 11.3 & 0.33 & 0.08 & 0.18 & 0.54 & 2.56 \\
\hline Unicid 350 & 7.5 & 0.22 & 0.09 & 0.19 & 0.87 & 4.11 \\
\hline Calfax & 12.4 & 0.22 & 0.07 & 0.12 & 0.21 & 1.17 \\
\hline Calfax & 6.1 & 0.11 & 0.07 & 0.11 & 0.20 & 1.18 \\
\hline Calfax & 3.5 & 0.06 & 0.07 & 0.16 & 10.1 & 62.9 \\
\hline
\end{tabular}

\section{Table 5}

Particle size summary for anionic surfactant based emulsions created using SFEE.

\begin{tabular}{|c|c|c|c|c|c|c|c|} 
Surfactant & $\begin{array}{c}\text { Surfactant } \\
\text { Amount } \\
{[\mathrm{pph}]}\end{array}$ & $\begin{array}{c}\text { Surfactant Loading } \\
{[\mathrm{mmol} / \mathrm{g} \text { resin }]}\end{array}$ & $\begin{array}{c}\mathrm{D}_{10} \\
{[\mu \mathrm{m}]}\end{array}$ & $\begin{array}{c}\mathrm{D}_{50} \\
{[\mu \mathrm{m}]}\end{array}$ & $\begin{array}{c}\mathrm{D}_{90} \\
{[\mu \mathrm{m}]}\end{array}$ & $\begin{array}{c}\text { Ppan } \\
\text { Emulsified } \\
\text { Material } \\
{[\%]}\end{array}$ \\
\hline SDBS & 7.5 & 0.22 & 0.07 & 0.11 & 0.19 & 1.09 & 100 \\
\hline SDBS & 4.0 & 0.11 & 2.55 & 30.3 & 552 & 18.1 & 10 \\
\hline Unicid 350 & 17.7 & 0.52 & 0.12 & 0.39 & 68.9 & 176 & 50 \\
\hline Unicid 350 & 12.4 & 0.36 & 0.21 & 0.89 & 319 & 358 & 50 \\
\hline Unicid 350 & 8.1 & 0.24 & 0.24 & 9.67 & 131 & 13.6 & 10 \\
\hline Calfax & 19 & 0.22 & 0.08 & 0.16 & 0.39 & 2.29 & 100 \\
\hline Calfax & 11.3 & 0.13 & 0.08 & 0.19 & 0.52 & 2.32 & 100 \\
\hline Calfax & 5.1 & 0.06 & 0.20 & 0.30 & 3.90 & 12.3 & 100 \\
\hline
\end{tabular}

\section{Table 6}

Particle size summary for non-ionic surfactant based emulsions created using SE.

\begin{tabular}{|c|c|c|c|c|c|c|}
\hline Surfactant & $\begin{array}{c}\text { Surfactant } \\
\text { Amount } \\
{[\mathrm{pph}]}\end{array}$ & $\begin{array}{c}\text { Surfactant Loading } \\
{[\text { mmol/g polyester }]}\end{array}$ & $\begin{array}{c}\mathrm{D}_{10} \\
{[\mu \mathrm{m}]}\end{array}$ & $\begin{array}{c}\mathrm{D}_{50} \\
{[\mu \mathrm{m}]}\end{array}$ & $\begin{array}{c}\mathrm{D}_{90} \\
{[\mu \mathrm{m}]}\end{array}$ & Span \\
\hline Igepal CO-890 & 43 & 0.22 & 0.07 & 0.11 & 0.17 & 0.91 \\
\hline Igepal CO-890 & 22 & 0.11 & 0.06 & 0.12 & 0.22 & 1.32 \\
\hline Igepal CO-890 & 7.5 & 0.04 & 0.09 & 0.31 & 277 & 898 \\
\hline Brij 58 & 24 & 0.22 & 0.07 & 0.11 & 0.18 & 1.03 \\
\hline Brij 58 & 12 & 0.11 & 0.06 & 0.12 & 0.24 & 1.45 \\
\hline Brij 58 & 7.5 & 0.07 & 0.10 & 0.40 & 244 & 617 \\
\hline Synperonic F-108 & 310 & 0.22 & 0.10 & 0.30 & 1.28 & 3.99 \\
\hline
\end{tabular}




\section{Table 7}

Particle size summary for non-ionic surfactant based emulsions created using SFEE.

\begin{tabular}{|c|c|c|c|c|c|c|c|}
\hline Surfactant & $\begin{array}{c}\text { Surfactant } \\
\text { Amount } \\
{[\mathrm{pph}]}\end{array}$ & $\begin{array}{c}\text { Surfactant Loading } \\
{[\text { mmol/g polyester }]}\end{array}$ & $\begin{array}{c}\mathrm{D}_{10} \\
{[\mu \mathrm{m}]}\end{array}$ & $\begin{array}{c}\mathrm{D}_{50} \\
{[\mu \mathrm{m}]}\end{array}$ & $\begin{array}{c}\mathrm{D}_{90} \\
{[\mu \mathrm{m}]}\end{array}$ & $\begin{array}{c}\text { Approx. } \\
\text { Span } \\
\text { Percent } \\
\text { Emulsion } \\
{[\%]}\end{array}$ \\
\hline Igepal CO-890 & 42 & 0.22 & 0.09 & 0.3 & 1.7 & 5.4 & 25 \\
\hline Igepal CO-890 & 32 & 0.16 & 0.10 & 0.2 & 62.5 & 312 & 25 \\
\hline Igepal CO-890 & 22 & 0.11 & 0.10 & 0.2 & 74.6 & 373 & 25 \\
\hline Brij 58 & 24 & 0.22 & 0.13 & 9.7 & 354 & 36.5 & 5 \\
\hline Brij 58 & 35 & 0.32 & 0.10 & 0.4 & 734 & 1830 & 5 \\
\hline
\end{tabular}

\section{Table 8}

Zeta potential data for SE samples tested at various $\mathrm{pH}$ values, and temperatures for six different surfactants at their respective molar loadings: SDBS [0.22 mmol/g resin], Unicid 350 [0.22 $\mathrm{mmol} / \mathrm{g}$ resin], Calfax [0.11 mmol/g resin], Igepal CO-890 [0.22 mmol/g resin], Brij 58 [0.22 mmol/g resin], Synperonic F-108 [0.22 mmol/g resin].

\begin{tabular}{|c|c|c|c|c|}
\hline \multirow{2}{*}{ Name } & \multicolumn{3}{|c|}{ Tested Emulsion Zeta Potentials [mV] } \\
\cline { 2 - 5 } & $60^{\circ} \mathrm{C}$ & $120^{\circ} \mathrm{C}$ & $60^{\circ} \mathrm{C}$ & $120^{\circ} \mathrm{C}$ \\
\cline { 2 - 5 } SDBS & -40.1 & -29.8 & -46.7 & -10.7 \\
\hline Unicid 350 & -48.9 & -22.6 & -46.5 & -22.6 \\
\hline Calfax DB-45 & -29.2 & -30.5 & -26.9 & -17.7 \\
\hline Igepal CO-890 & -25.5 & -9.6 & -26.5 & -13.9 \\
\hline Brij 58 & -22.6 & -20.3 & -26.7 & -21.8 \\
\hline Synperonic F-108 & -16.5 & -12.2 & -12.2 & -4.6 \\
\hline
\end{tabular}




\section{Table 9}

Zeta potential data for SFEE samples tested at various $\mathrm{pH}$ values, and temperatures for six different surfactants at their respective molar loadings: SDBS [0.22 mmol/g resin], Unicid $350[0.52 \mathrm{mmol} / \mathrm{g}$ resin], Calfax [0.13 mmol/g resin], Igepal CO-890 [0.22 mmol/g resin], Brij 58 [0.22 mmol/g resin].

\begin{tabular}{|c|c|c|c|c|}
\hline \multirow{2}{*}{ Name } & \multicolumn{4}{|c|}{ Tested Emulsion Zeta Potentials [mV] } \\
\cline { 2 - 5 } & \multicolumn{3}{|c|}{$\mathrm{pH} \mathrm{7}$} & \multicolumn{2}{c|}{$\mathrm{pH} 10$} \\
\cline { 2 - 5 } & $60^{\circ} \mathrm{C}$ & $120^{\circ} \mathrm{C}$ & $60^{\circ} \mathrm{C}$ & $120^{\circ} \mathrm{C}$ \\
\hline SDBS & -50.9 & -44.6 & -37.6 & -18.5 \\
\hline Unicid 350 & -26.3 & -22.5 & -37.3 & -16.2 \\
\hline Calfax DB-45 & -60.1 & -49.5 & -58.1 & -41.6 \\
\hline Igepal CO-890 & -24.5 & -19.9 & -22.1 & -14.2 \\
\hline Brij 58 & -36 & -33.5 & -29.4 & -20.0 \\
\hline Synperonic F-108 & N/A & N/A & N/A & N/A \\
\hline
\end{tabular}

